\title{
SIRT1 Activating compounds reduce oxidative stress mediated neuronal loss in viral induced CNS demyelinating disease
}

\author{
Reas S Khan ${ }^{1}$, Kimberly Dine ${ }^{1}$, Jayasri Das Sarma ${ }^{2^{*}}$ and Kenneth S Shindler ${ }^{{ }^{*}}$
}

\begin{abstract}
Background: Multiple sclerosis (MS) is characterized by central nervous system inflammation and demyelination, and increasing evidence demonstrates significant neuronal damage also occurs and is associated with permanent functional impairment. Current MS therapies have limited ability to prevent neuronal damage, suggesting additional neuroprotective therapies are needed. Compounds that activate the NAD+-dependent SIRT1 deacetylase prevent neuronal loss in an autoimmune-mediated MS model, but the mechanism of this effect is unknown, and it is unclear whether SIRT1 activating compounds exert similar effects in demyelinating disease induced by other etiologies. We measured neuronal loss in C57BL/6 mice inoculated with a neurotropic strain of mouse hepatitis virus, MHV-A59, that induces an MS-like disease.
\end{abstract}

Results: Oral treatment with the SIRT1 activating compound SRTAW04 significantly increased SIRT1 activity within optic nerves and prevented neuronal loss during optic neuritis, an inflammatory demyelinating optic nerve lesion that occurs in MS and its animal models. MHV-A59 induced neuronal loss was associated with reactive oxygen species (ROS) accumulation, and SRTAW04 treatment significantly reduced ROS levels while promoting increased expression of enzymes involved in mitochondrial function and reduction of ROS. SRTAW04 exerted similar protective effects in EAE spinal cords, with decreased demyelination.

Conclusions: Results demonstrate that SIRT1 activating compounds prevent neuronal loss in viral-induced demyelinating disease similar to their effects in autoimmune-mediated disease. One mechanism of this neuroprotective effect involves increasing mitochondrial biogenesis with reduction of oxidative stress. SIRT1 activators represent a potential neuroprotective therapy for MS. Understanding common mechanisms of these effects in distinct disease models will help identify targets for more specific therapies.

Keywords: Demyelinating disease, Mouse hepatitis virus, SIRT1, Neuroprotection, Oxidative stress, Optic neuropathy

\section{Background}

Multiple sclerosis (MS) is an inflammatory demyelinating disease of the central nervous system (CNS) [1]. Significant neuronal damage also occurs in MS, and correlates with permanent neurologic dysfunction [2-6]. Current therapies reduce the inflammatory component of MS, but their ability to prevent neuronal damage is limited

\footnotetext{
* Correspondence: dassarmaj@iiserkol.ac.in; Kenneth.Shindler@uphs.upenn.edu; ${ }^{2}$ Department of Biological Science, Indian Institute of Science Education and Research-Kolkata (IISER-K), Mohanpur Campus Mohanpur, Nadia, West Bengal 741252, India

'Department of Ophthalmology, Scheie Eye Institute and FM Kirby Center for Molecular Ophthalmology, Stellar-Chance Laboratories, University of Pennsylvania, Philadelphia, PA 19104, USA
}

[7-10], suggesting additional therapies with neuroprotective benefits are needed.

While evidence suggests MS is an autoimmune disease against CNS myelin, the exact etiology is not known. Other evidence suggests genetic and viral-mediated triggers [11]. Because the etiology is unknown, several MS animal models are used. The most common MS model, experimental autoimmune encephalomyelitis (EAE), is an autoimmune driven CNS demyelinating disease [12] that also exhibits neuronal damage [13-15]. Another MS model is induced by infection with a neurotropic strain of mouse hepatitis virus (MHV), MHV-A59 [16,17]. While MHVA59 induces CNS inflammation and demyelination similar to EAE, the etiology is distinct, involving direct neuronal 
infection, and the demyelination is not dependant on an intact immune system [18]. Therefore, these models provide unique and contrasting systems for studying potential neuroprotective strategies for MS.

Optic nerve is a frequent site of MS lesions, and optic neuritis is a common presenting sign of MS [19]. Similarly, optic neuritis occurs at high frequency in both EAE and MHV models of MS [20-22]. In addition to optic nerve inflammation, these studies demonstrate significant axonal damage, with loss of retinal ganglion cell (RGC) neurons that comprise the optic nerve also found in EAE optic neuritis, but not examined in the MHV model. RGCs are readily quantified, allowing optic neuritis to serve as a representative lesion for assessing neuronal damage $[5,6,14,20,22]$.

Activation of SIRT1, an NAD-dependent deacetylase involved in cell stress responses, attenuates neuronal damage in EAE [23-25], although mechanisms mediating this effect are not known. SIRT1 reduces oxidative stress and promotes mitochondrial biogenesis in muscle [26] and cultures of neuronal cells [27], and oxidative stress plays a role in neuronal degeneration in MS and EAE [28-30], suggesting SIRT1 activation may prevent neuronal damage by increasing mitochondrial function and reducing oxidative stress.

While mechanisms of neuronal damage in MHV-A59induced demyelinating disease are not fully understood, oxidative stress is a common mechanism of cellular injury and is likely to occur in MHV-A59 infection. The current studies characterize mechanisms of neuronal loss in viral-induced demyelinating disease, and examine the ability of SIRT1 activating compounds to prevent neuronal loss, reduce oxidative stress, and regulate proteins that promote mitochondrial function.

\section{Methods \\ Mice}

Four-week-old female C57BL/6 (B6) mice were purchased from the Jackson Laboratory (Bar Harbor, ME). Treatment of the animals was reviewed and approved by the Institutional Animal Care and Use Committee at the University of the Pennsylvania, where the mice were maintained and fed ad libitum in an approved animal care facility.

\section{Inoculation and treatment of mice}

MHV-free mice were inoculated intracranially with $50 \%$ of the half lethal dose of the demyelinating strain MHV-A59 [2000 plaque forming units (pfu)], a related non-demyelinating strain MHV2 (100 pfu) used as a negative control, or isogenic recombinant strains containing a fluorescent tag: RSA59 (20,000 pfu) used as a positive control and RSMHV2 (250 pfu) as negative control. Due to differences in replication and elimination, these doses result in equivalent viral loads in the CNS, and inoculation of each strain was performed as described previously $[31,32]$. Mice were monitored daily for mortality and signs of disease [16,17]. Mock-infected controls were inoculated similarly but with an uninfected cell lysate at a comparable dilution. SRTAW04 (Sirtris, a GSK company, Cambridge, MA) was prepared in PBS containing 0.5\% methyl cellulose and $0.1 \%$ tween 80 . Mice were treated with SRTAW04, $100 \mathrm{mg} / \mathrm{kg} / \mathrm{mouse} /$ day by oral gavage. The dose was chosen based on previously measured pharmacokinetics of the drug and its ability to activate SIRT1 which has been used previously with maximal effects $[27,33,34]$. Seven day and 30 day treatment groups received SRTAW04 starting from day 1 until sacrifice. To evaluate whether the SRTAW04 target is SIRT1 and its activation, one group of mice received SIRT1 inhibitor EX527 (10 mg/kg/day i.p.) for 30 days [35]. EX527 has the highest inhibitory activity for SIRT1 compared to other analogues and previous studies have shown that EX527 treatment alone does not result in the acetylation of SIRT1/2 target p53 [36,37]. We have previously shown that SIRT1 inhibitors or conditional deletion of the SIRT1 gene, do not exacerbate RGC loss in optic nerve disease models [24,38].

\section{RGC labeling and counting}

RGCs were labeled and counted as described previously [20]. Briefly, $2.5 \mu \mathrm{L}$ of $1.25 \%$ hydroxystilbamidine (Fluorogold; Molecular Probes, Eugene, OR) in sterile water was injected stereotactically into each superior colliculus through holes drilled in the skull. Mice were killed 7 or 30 days after infection and each eye was removed and fixed in $4 \%$ paraformaldehyde. Retinas were isolated, prepared as flattened wholemounts, viewed with a fluorescence microscope (Eclipse E600; Nikon, Tokyo, Japan), and photographed at $20 \mathrm{X}$ magnification in 12 standard fields: $1 / 6,3 / 6$, and $5 / 6$ of the retinal radius from the center of the retina in each quadrant. RGC numbers shown in each experiment represent the total number of RGCs counted per eye (RGCs/0.74 mm2). RGCs were counted by a masked investigator using image analysis software (ImagePro Plus 5.0; Media Cybernetics, Silver Spring, MD). Alternatively, to confirm RGC numbers, RGC's were immunolabelled with antibodies to Brn3a. Retinas were dissected and flat as previously reported [39]. The retinas were washed with PBS, permeabilized in $0.5 \%$ TritonX 100 in PBS by freezing them for $15 \mathrm{~min}$ at $-70^{\circ} \mathrm{C}$, rinsed in PBS containing $0.5 \%$ Triton, and incubated overnight at $4^{\circ} \mathrm{C}$ with goat-antiBrn3a antibody (Santa Cruz) diluted 1:100 in blocking buffer (PBS, $2 \%$ bovine serum albumin, $2 \%$ Triton $X 100$ ). The retinas were washed three times in PBS, incubated for 2 hours at room temperature (RT) with anti-goat secondary antibody diluted 1:500 in blocking buffer, washed in PBS and mounted vitreous side up on slides in anti-fading solution. Cells were 
counted in 12 fields as described above for fluorogold labeled RGCs.

\section{Histopathological analysis}

Mice were killed at day 30 post inoculation (p.i.), and were perfused transcardially with PBS followed by PBS containing 4\% paraformaldehyde (PFA). Spinal cords or optic nerves were collected, postfixed in 4\% PFA overnight and embedded in paraffin. Spinal cord tissues were sectioned at $5 \mu \mathrm{m}$ and stained with either Luxol Fast Blue (LFB) to detect demyelination or with anti-neurofilament antibodies to detect loss of axons. Areas of demyelination in LFB staining were quantified using a $0-3$ point scale as described earlier [21] 0 - no demyelination; 1 - rare foci of demyelination; 2 - a few foci of demyelination; and 3 large (confluent) areas of demyelination. Two to three sections were examined from each of three spinal cord levels (cervical, thoracic and lumbar) for each mouse. Neurofilament staining was done according to a previously published protocol [40]. Briefly, paraffin embedded sections were dewaxed, rehydrated, and then permeabilized with 0.5\% tween-20 in PBS. The sections were blocked with blocking reagent from Vectastain Elite $\mathrm{ABC}$ kit and then incubated in the rabbit anti-neurofilament antibody 1:100 (AbCam) at $4^{\circ} \mathrm{C}$ overnight, washed, and incubated with goat biotinylated anti-rabbit secondary antibody (Invitrogen) for 2 hours at $\mathrm{RT}$. The $\mathrm{ABC}$ detection was performed using the Vectastain Elite $A B C$ kit and $D A B$ (diaminobenzidine) substrate kit (both Vector Laboratories, Burlingame, CA) according to manufacturer's instructions. To characterize virus induced inflammation, spinal cords from 7 day p.i. mice were stained with $\mathrm{H} \& \mathrm{E}$ as described previously $[21,32]$ and scored using an inflammation scale: 0 - no inflammation, 0.5 - few inflammatory cells, 1 - inflammatory cells localized near white matter, 1.5 - small patches of inflammatory cells, 2 - large inflammatory plaques, 3 - diffuse inflammation. Experiments were repeated three times with 3-5 mice in each group. All slides were coded and read in a blinded manner. 30 days p.i. spinal cord sections were also stained with a macrophage/microglial marker anti-Iba1 (Wako, Japan) as described previously [18]. Iba1 stained sections were counterstained with hematoxylin (Vector laboratories). Optic nerve tissues were sectioned as $5 \mu \mathrm{m}$ longitudinal sections and stained with H\&E, LFB and antineurofilament antibody using methods described above.

\section{SIRT1 activity assay}

SIRT1 activity was determined with a SIRT1 Fluorometric Kit (BIOMOL, Plymouth Meeting, PA) performed according to the manufacturer's instructions. Optic nerves were homogenized in SIRT1 assay buffer, then incubated for $10 \mathrm{~min}$ at $37^{\circ} \mathrm{C}$ to allow degradation of any contaminant $\mathrm{NAD}^{+}$. Protein concentration was determined using a
BCA protein assay kit (Thermo Scientific, Rockford, IL). Homogenates (20-30 $\mu$ g protein/well) were then incubated with $100 \mu \mathrm{M}$ Fluor de Lys-SIRT1 substrate (Enzo Life Sciences) in the presence or absence of $\mathrm{NAD}^{+}$ to determine $\mathrm{NAD}^{+}$dependent SIRT1 activity. The reaction was terminated by adding Fluor de Lys Developer (Enzo Life Sciences) and $2 \mathrm{mM}$ nicotinamide after $60 \mathrm{~min}$ of incubation at $37^{\circ} \mathrm{C}$ and fluorescence values were read on a fluorometric plate reader (Wallac Victor ${ }^{2} 1420$ multi label counter, Perkin Elmer, Waltham, MA) with an excitation wavelength of $360 \mathrm{~nm}$ and an emission wavelength of $460 \mathrm{~nm}$. SIRT1 inhibitors nicotinamide $(2 \mathrm{mM})$, suramin $(100 \mu \mathrm{M})$, and sirtinol $(100 \mu \mathrm{M})$ were used to confirm the specificity of the reaction.

\section{MitoSOX staining}

MitoSOX Red (Invitrogen) superoxide indicator is a fluorogenic dye for selective detection of superoxide, a reactive oxygen species (ROS), in mitochondria. MitoSOX Red reagent is cell permeable and is selectively targeted to the mitochondria, where it is oxidized by superoxide and exhibits red fluorescence. MitoSOX staining was done according to previously published protocols [38]. Briefly, MitoSOX reagent was diluted to a final concentration of $5 \mu \mathrm{M}$ in PBS and optic nerves were incubated for $30 \mathrm{~min}$ at $37^{\circ} \mathrm{C}$. After incubation, nerves were washed three times with PBS, fixed with $4 \%$ paraformaldehyde for $10 \mathrm{~min}$ and mounted in Optimal Cutting Temperature (OCT) compound (Ted Pella, Inc., Redding, CA). $5 \mu \mathrm{M}$ crosssections were made, mounted onto glass slides with Mowiol mounting medium, and observed under an Eclipse E600 (Nikon) fluorescence microscope using excitation $510 \mathrm{~nm} / \mathrm{emission} 580 \mathrm{~nm}$, and photographed at 20X magnification. Photographs were taken centered within each optic nerve cross section by a blinded investigator using a standard exposure, and staining was quantified by calculating the optical density using Image J software (nih.gov).

\section{Western blot analysis}

Optic nerves or retinas in RIPA buffer $(150 \mathrm{mM} \mathrm{NaCl}$, $1 \%$ NP-40, 0.5\% desoxycholic acid, 0.1\% SDS and $50 \mathrm{mM}$ Tris, $\mathrm{pH} 8$ ) were ultrasonicated on ice 5 times for $5 \mathrm{sec}$ each at 10 -sec intervals to obtain total protein extracts. Cell lysates were then centrifuged at $14,000 \mathrm{~g}$ for $10 \mathrm{~min}$ at $4^{\circ} \mathrm{C}$, and the protein concentration of the supernatant was determined using a BCA protein assay kit (Thermo Scientific). Sodium dodecyl sulfate polyacrylamide gel electrophoresis was performed on $10 \%$ polyacrylamide gels, with $20 \mu \mathrm{g}$ of protein per lane, and then transferred to nitrocellulose High bound ECL membranes (GE Healthcare Biosciences, Pittsburgh, PA). The membrane was blocked with Odyssey Blocking Buffer (Licor Biotechnology, Lincoln, NE) for $1 \mathrm{hr}$ at RT and probed with rabbit polyclonal antibodies against SIRT1 (1:1500) (Abcam, 
Cambridge, MA), SOD2 (1:1000) (GeneTex, Irvine, CA) and PGC-1 $\alpha$ (1:1000) (Novus Biologicals, Littleton, CO) and mouse monoclonal antibodies against succinate dehydrogenase B (SDHb) (1:1000) (Abcam) overnight at $4^{\circ} \mathrm{C}$. After being washed three times using PBS, the membranes were incubated with IRDye $800 \mathrm{CW}$ goat anti-rabbit IgG or IRDye 600 goat anti-mouse IgG (Licor) as secondary antibodies at a dilution of 1:5000 for $1 \mathrm{hr}$ at RT. After being washed a further three times with PBS, fluorescence was visualized using Odyssey infrared imaging system (Licor). For normalization of signals, blotted membranes were stained for $\beta$-actin (Sigma). The intensity of each band was determined using Image J software (nih.gov).

\section{Statistics}

Data are expressed as means \pm SEM. Differences in RGC numbers, SIRT1 activity, and protein expression were assessed using one-way ANOVA followed by Student Neuman-Keuls post-hoc test. Statistical differences were considered significant at $\mathrm{P}<0.05$.

\section{Results}

MHV-A59 infection induces optic nerve inflammation and neuronal loss

Optic nerves of MHV-A59 infected mice develop inflammation peaking by 5-7 days after inoculation, followed by significant demyelination at day 30; whereas MHV2 infected mice have almost no inflammation nor demyelination [21]. We found similar results in optic nerves stained by H\&E and LFB in the current studies (data not shown). To examine whether infection with demyelinating strains of MHV also results in neuronal loss, RGCs were labeled in four-week-old, virus-free, C57BL/6 mice and one week later mice were inoculated with MHV-A59, RSA59 or MHV2. Mice were sacrificed 30 days postinfection and RGCs were counted. Significant differences were found in total RGC numbers counted in 12 standardized retinal fields, but not within any one region of the retina. MHV-A59 infected mice had significantly fewer surviving RGCs compared to noninfected mice (Figure 1). Mice infected with the nondemyelinating control strain MHV2 did not show RGC loss compared to non-infected controls. Consistent with RGC loss induced by MHV-A59, a recombinant strain, RSA59, which is isogenic to MHV-A59 except for an EGFP fluorescent marker and which has similar demyelinating properties $[32,41]$ and ability to induce optic neuritis [42], also induced significant RGC loss compared to noninfected control and MHV2 infected mice (Figure 1).

SRTAW04 treatment increases SIRT1 activity in optic nerves SIRT1 activators are compounds that promote SIRT1 deacetylase activity [33] in vitro. In vivo, SIRT1 activators prevent RGC loss during EAE optic neuritis [23-25],
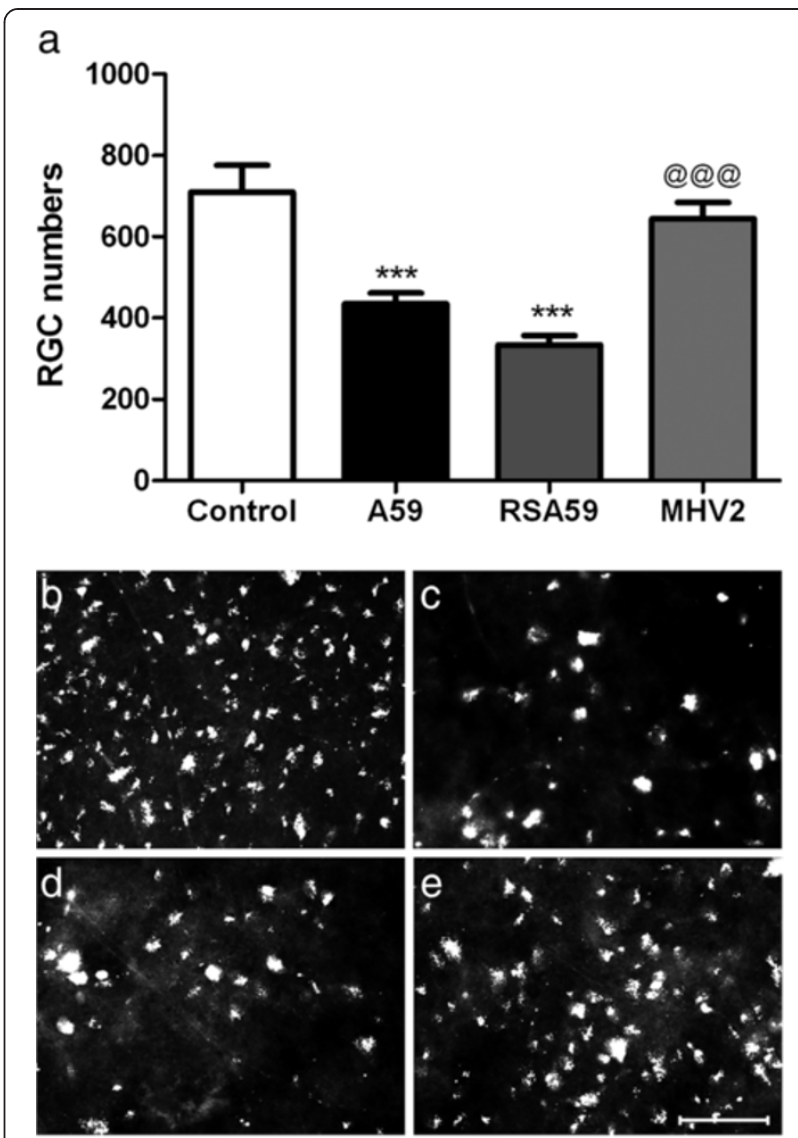

Figure 1 MHV-A59 infection induces RGC loss. (a) Inoculation with demyelinating strains MHV-A59 $(n=12)$, and its isogenic recombinant strain RSA59 ( $n=10)$, lead to significantly decreased (***p $<0.001)$ RGC numbers compared to non-infected control mice $(n=10)$, and mice inoculated with the non-demyelinating control strain MHV2 $(n=16)$ (@@ $\mathrm{p}<0.001)$. Mice infected with MHV2 did not show RGC loss compared to non-infected controls. Fluorescently labeled RGCs are shown from a representative field in (b) non-infected control and (e) MHV2 infected retina, whereas fewer RGCs are seen in corresponding areas of retina in MHV-A59 (c) or RSA59 infected mice (d). Scale bars $10 \mu \mathrm{m}$ for b-e.

but specific increase in SIRT1 activity in optic nerve was not assessed. To determine the timing of SIRT1 activity changes in optic nerve, wild-type mice were treated with SIRT1 activator SRTAW04 by oral gavage at a dose of $100 \mathrm{mg} / \mathrm{kg} /$ day for 4 days and mice were killed on the 4th day at different time intervals after the final dose. Optic nerves were isolated and SIRT1 activity was determined with a SIRT1 fluorometric substrate assay kit. Results show a significant increase in SIRT1 activity $1 \mathrm{hr}$ after SRTAW04 treatment (Figure 2a). Increased activity was transient, and declined back to control levels after $2 \mathrm{hr}$.

We next examined SIRT1 activity in the optic nerves of MHV-A59 infected mice after 30 days of SRTAW04 treatment. 4 week old mice were infected with MHVA59 and were treated with SRTAW04 starting from day 


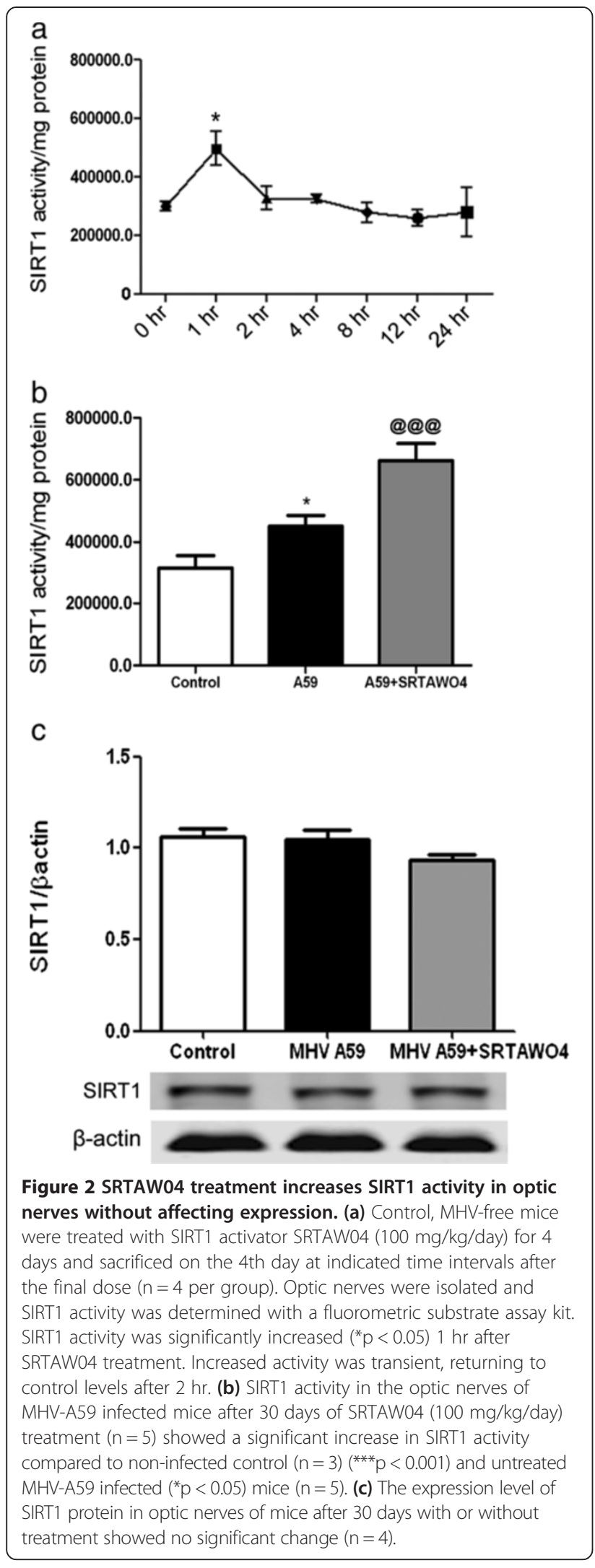

1 with $100 \mathrm{mg} / \mathrm{kg} /$ day for 30 days. On the 30th day mice were sacrificed $1 \mathrm{hr}$ after SRTAW04 treatment and protein was extracted from optic nerves for SIRT1 activity assay. Optic nerves of MHV-A59 mice treated with SRTAW04 showed a significant increase in SIRT1 activity compared to control and untreated MHV-A59 infected mice (Figure 2b). Interestingly, untreated MHV-A59 infected mouse optic nerves also showed a smaller but significant increase compared to control, possibly as a natural defense mechanism. We also examined levels of SIRT1 in retinas and optic nerves of mice after 7 or 30 days with or without treatment by SRTAW04. SIRT1 protein expression levels measured by Western blotting showed no significant differences between any treatment groups in day 30 optic nerves (Figure 2c), with similar lack of change in day 7 optic nerves and in retinas at either time point (data not shown).

\section{SRTAW04 treatment prevents neuronal loss in MHV-A59 infected mice}

We have shown that SIRT1 activators attenuate RGC loss during EAE optic neuritis [23-25] however, neuronal damage in the MHV model of MS occurs by different mechanisms than in EAE, including direct viral infection of neurons and macrophage-mediated myelin stripping of axons [18]. The ability of SRTAW04 to attenuate neuronal loss in MHV-A59 infected mice was therefore examined. RGCs of 4 week old C57BL/6 mice were labeled with fluorogold and mice were inoculated with MHV-A59 one week later. The treatment group was administered SRTAW04 $(100 \mathrm{mg} / \mathrm{kg} /$ day $)$ by oral gavage starting from day 1 for 30 days. The decrease in RGC numbers in untreated MHV-A59 mice, compared to controls, was significantly attenuated by SRTAW04 treatment (Figure 3a). To further confirm the neuroprotective effect of SRTAW04, 4 week old C57BL/6 mice were inoculated with recombinant strain of MHV, RSA59 and the treatment group was administered the same dose of SRTAW04 for 30 days with and without SIRT1 inhibitor EX527 $(10 \mathrm{mg} / \mathrm{kg} /$ day i.p.). After 30 days RGCs were labeled by Brn3a staining and counted. Consistent with MHV-A59 results (Figure 3a) RSA59 induced a significant decrease in RGCs and treatment with SRTAW04 attenuated RGC loss. The SRTAW04 treatment group receiving EX527 showed a significant decrease in RGC numbers compared to the group that only received SRTAW04 (Figure 3b, c) demonstrating that the RGC protective effect of SRTAW04 is dependent on SIRT1. Treatment with SIRT1 inhibitor alone does not further reduce RGC survival (data not shown), similar to prior studies $[24,38]$.

\section{Effects of SRTAW04 on neuronal loss in the optic nerve} To examine whether viral induced $\mathrm{ON}$ also leads to axonal loss, optic nerves were stained with anti-neurofilament 


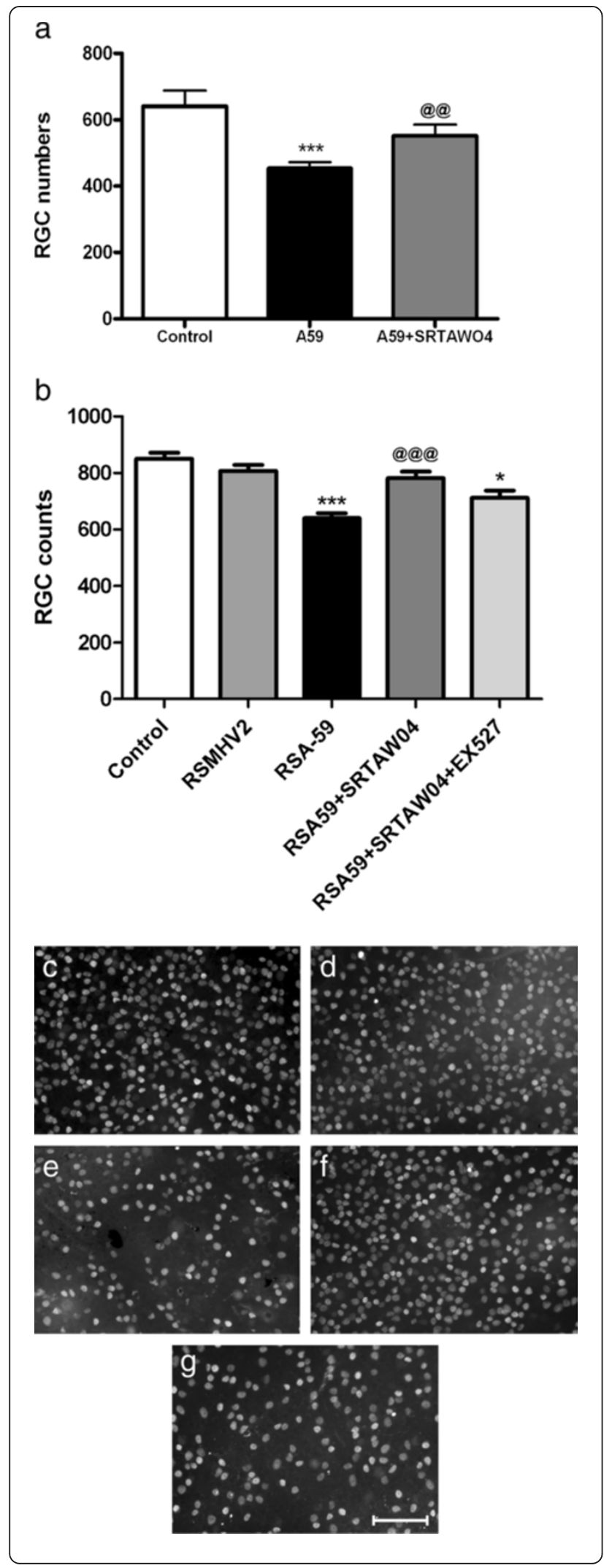

Figure 3 SRTAW04 treatment prevents neuronal loss in MHV-A59 infected mice. (a) MHV-A59 $(n=28)$ infection significantly decreases RGC numbers compared to non-infected control mice $(n=18)\left({ }^{* * *} p<0.001\right)$. SRTAW04 treatment $(100 \mathrm{mg} / \mathrm{kg} /$ day $)$ for 30 days $(\mathrm{n}=16)$ results in significant $\left({ }^{@} \mathrm{p}<0.01\right.$ ) attenuation of RGC loss. (b) C57BL/6 mice were inoculated with recombinant strain of MHV, RSA59 and the treatment group was administered SRTAW04 (100 mg/kg/day) for 30 days with and without SIRT1 inhibitor EX527 (10 mg/kg/day i.p.). After 30 days the RGCs were labeled by Brn3a staining and counted. RSA59 $(n=12)$ induced a significant decrease in RGCs $\left({ }^{* * *} p<0.001\right)$ compared to control $(n=8)$ and MHV2 infected $(n=6)$ mice. Treatment with SRTAW04 ( $n=10)$ significantly $@ @ @ p<0.001)$ attenuated RGC loss. The SRTAW04 treatment group receiving EX527 $(n=10)$ showed a significant decrease $\left({ }^{*} \mathrm{p}<0.05\right)$ in RGC numbers compared to the group that only received SRTAW04 demonstrating that the RGC protective effect of SRTAW04 is dependent on SIRT1. Brn3a labeled RGCs from a representative retinal field in (c) control, (d) RSMHV2 infected, (e)RSA59 infected, (f) RSA59 infected, with SRTAW04 treatment and (g) RSA59 infected, with SRTAW04 + EX527 treatment. Fewer RGCs are seen in a corresponding area of retina in an MHV-A59 infected mouse. Retina from an MHV-A59 infected mouse treated with SRTAW04 (100 mg/kg/day) for 30 days shows numerous RGCs similar to the non-infected control whereas MHV-A59 infected mouse treated with SRTAW04+ EX527 for 30 days shows fewer RGCs. Scale bars $10 \mu \mathrm{m}$ for $\mathbf{c - g}$.

antibodies and the area of axonal staining was quantified as described previously [18]. Thirty days post inoculation, nerves from RSA59-infected mice showed significantly decreased axonal staining compared to control nerves or nerves from MHV2-infected mice (Figure 4a-c,f). SRTAW04 treatment showed a significant preservation of the axons whereas SRTAW04 treated mice that received EX527 co-treatment showed no change compared to the RSA59 infected group (Figure 4c-e,f).

\section{SRTAW04 treatment reduces accumulation of ROS in MHV-A59 infected optic nerves}

MitoSOX Red detection of superoxide within mitochondria was used to determine whether there is ROS accumulation in MHV-A59 induced optic neuritis. Mice were infected with MHV-A59 and sacrificed 7 days post-inoculation, when optic nerve inflammation is known to peak [21]. Optic nerves were isolated and stained with MitoSOX Red, which revealed an increase in the superoxide anion in MHV-A59 infected optic nerve compared to control optic nerves, and optic nerves from MHV-A59 infected mice treated daily with $100 \mathrm{mg} / \mathrm{kg}$ SRTAW04 had significantly less staining than untreated MHV-A59 infected mice (Figure 5a, b). We then examined accumulation of superoxide in optic nerves 30 days post-inoculation with MHV-A59 and with or without daily treatment with $100 \mathrm{mg} / \mathrm{kg}$ SRTAW04. Results again showed a significant increase in MitoSOX Red staining in optic nerves of mice infected with MHV-A59, as compared to control optic nerves, and treatment with SRTAW04 for 30 days significantly attenuated the accumulation of superoxide staining (Figure 5c, d). 


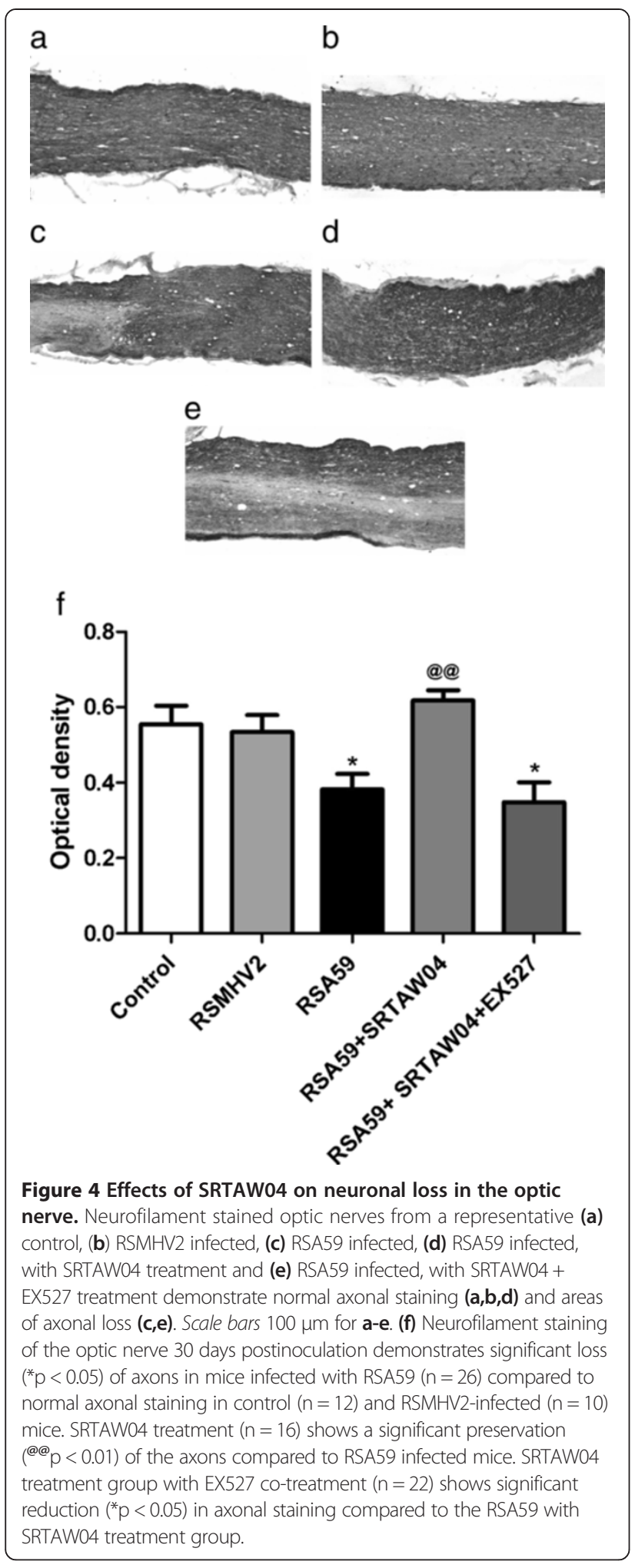

Effects of SRTAW04 on expression of markers of mitochondrial and anti-oxidant function

Optic nerves and retinas were isolated during the peak of inflammation, 7 days post-inoculation with MHV-A59, from mice treated with or without $100 \mathrm{mg} / \mathrm{kg}$ SRTAW04 daily, and expression levels of mitochondrial and antioxidant markers were measured. SDH is a key mitochondrial enzyme that catalyses oxidation of succinate to fumarate in the Krebs cycle, and feeds electrons to the respiratory chain ubiquinone (UQ) pool [43]. SDH functions not only in mitochondrial energy generation, but also has a role in oxygen sensing [44]. Protein levels of SDHb showed a significant decrease in the MHV-A59 infected group compared to controls. Treatment with SRTAW04 for seven days showed a significant increase of SDHb protein expression when compared to untreated MHV-A59 infected mice in both optic nerve and retina (Figure 6a,b,d). We also measured protein expression of SOD2, a mitochondrial protein which binds to superoxide byproducts of oxidative phosphorylation and converts them to hydrogen peroxide and diatomic oxygen [45]. Results showed a significant decrease in expression of SOD2 in optic nerves and retinas of MHV-A59 infected mice and treatment with SRTAW04 significantly attenuated that change (Figure 6a,c,e). The peroxisome proliferator activated receptor (PPAR) co-activator $1-\alpha$ (PGC1- $\alpha)$ is a transcriptional co-activator identified as an upstream regulator of mitochondrial number and function [46] and is activated by SIRT1-mediated deacetylation [26]. Results showed a significant decrease in PGC1- $\alpha$ expression during MHV-A59 infection, and treatment with SRTAW04 significantly increases the protein levels in retinas of 7 day treated mice (Figure 6a,f). PGC1- $\alpha$ levels in optic nerve were too low to be detected.

\section{Effects of SRTAW04 on demyelination in the spinal cord} In addition to optic nerve, MHV-A59 and RSA59 spread to spinal cord and induce significant demyelination and axonal injury after intracranial inoculation [18]. We therefore used spinal cord to confirm neuroprotective effects of SRTAW04 in RSA59 infected mice. Since tissue is limited in optic nerve, histologic studies were also performed using spinal cord, which has larger areas of white matter, to assess effects of SRTAW04 on demyelination. Spinal cords were isolated from mice infected with RSA59 for 30 days, treated with or without $100 \mathrm{mg} / \mathrm{kg}$ SRTAW04 daily, and demyelination levels were measured using LFB staining. Pathology was assessed in five to seven cross-sections of spinal cord from cervical, thoracic, and lumbar regions. Demyelinating plaques were quantified on a 0 to 3 scale in four quadrants from two spinal cord levels for each mouse. Spinal cord sections from the RSA59 infected group showed a significant increase in the demyelinating score compared to control and RSMHV2 infected groups (Figure 7a,b,d,f). The group receiving SRTAW04 showed a significant decrease in the demyelinating score compared to RSA59 infected group (Figure 7a,f, h). In contrast, SRTAW04 treated mice that also received the SIRT1 


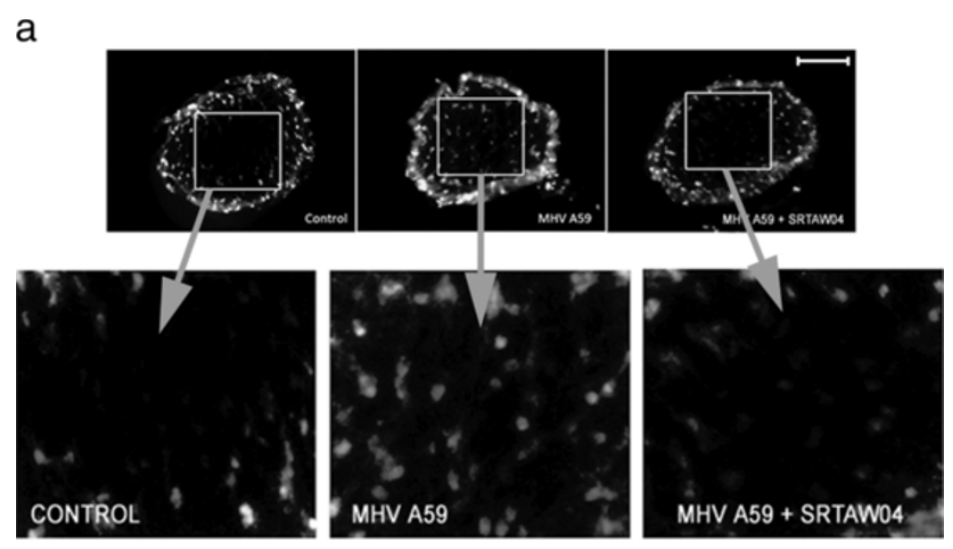

b

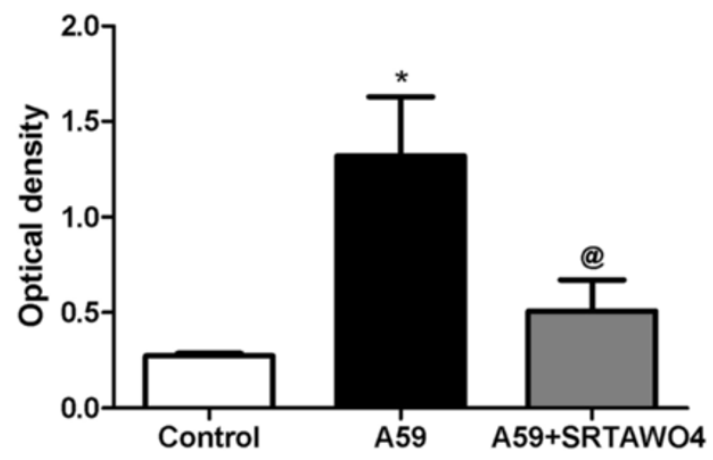

C

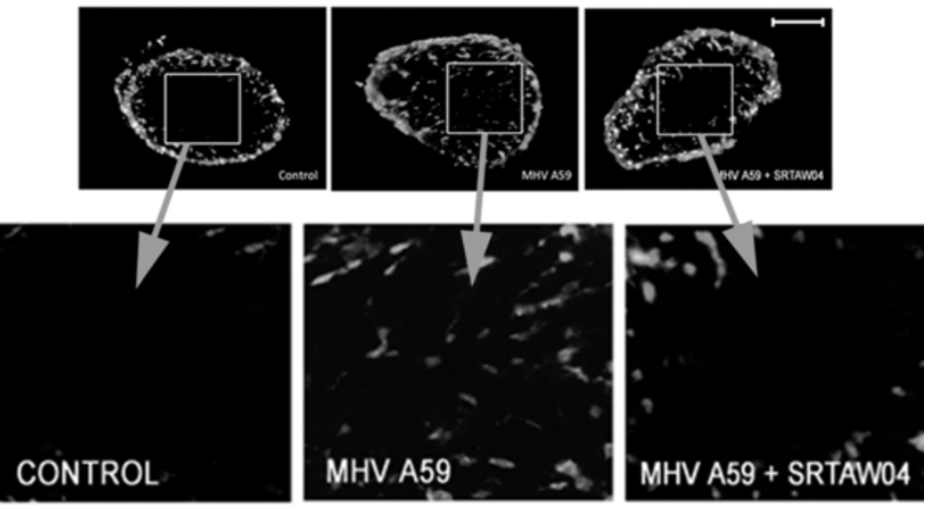

d

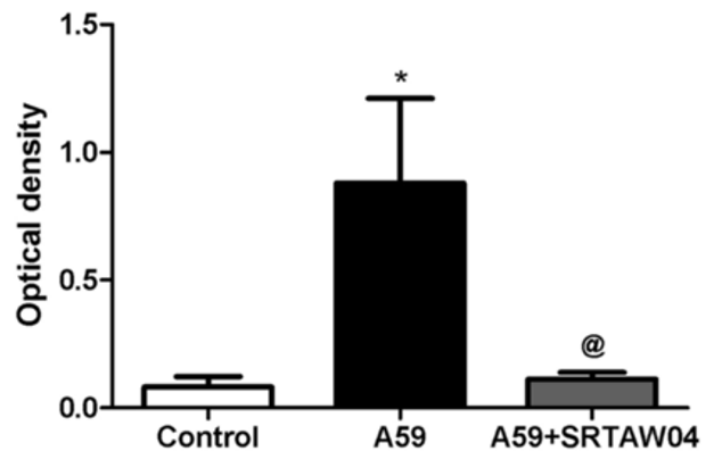

Figure 5 (See legend on next page.) 
(See figure on previous page.)

Figure 5 SRTAW04 treatment reduces ROS in MHV-A59 infected optic nerves both 7 and 30 days after infection. Mice were infected with MHV-A59 and sacrificed 7 days post-inoculation, when optic nerve inflammation is known to peak. (a) Representative images show optic nerves stained with MitoSOX Red. There is an increase in staining of the superoxide anion in MHV-A59 infected optic nerve compared to control optic nerves, with less staining present in optic nerve from an MHV-A59 infected mouse treated with SRTAW04 (100 mg/kg/day) for 7 days. (b) Quantification of MitoSOX Red staining in optic nerves. Average optical density in the central area of optic nerves was determined with image J software. Treatment with SRTAW04 $(n=8)$ significantly $\left({ }^{\circledR} p<0.05\right)$ attenuated the increase in superoxide anion staining induced during MHV-A59 $(n=6)$ infection relative to controls $\left({ }^{*} p<0.05\right)$. (c) Representative images show optic nerves stained with MitoSOX Red 30 days after infection with MHV-A59. There is increased staining in MHV-A59 infected optic nerve compared to control optic nerve, with less staining present in optic nerve from an MHV-A59 infected mouse treated with SRTAW04 (100 mg/kg/day) for 30 days. (d) Treatment with SRTAW04 $(n=8)$ significantly $\left({ }^{@} p<0.05\right)$ attenuated the increase in average optical density of superoxide anion staining observed in MHV-A59 $(n=7)$ infection relative to controls $(n=5)$ $\left({ }^{*} p<0.05\right)$. Scale bars $100 \mu \mathrm{m}$ for $\mathbf{a}, \mathrm{c}$
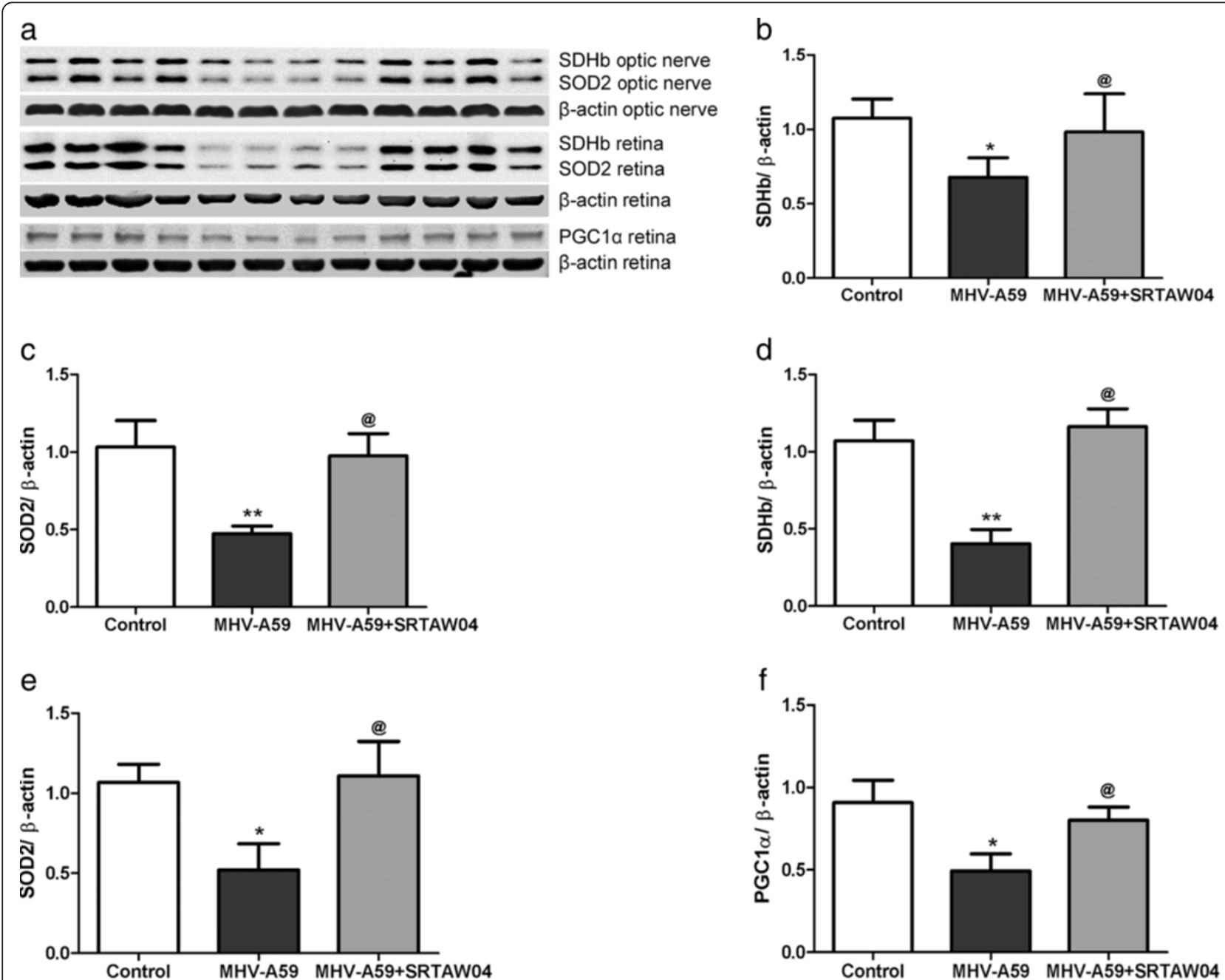

Figure 6 Effects of SRTAW04 on expression of markers of mitochondrial and anti-oxidant function. (a) Western blot of protein extracts from optic nerve and retina of control (lanes 1-4), MHV-A59 infected (lanes 5-8), and MHV-A59 infected + SRTAW04-treated (lanes 9-12) mice. Average levels of SDHb measured by Western blotting ( $n=4$ /group) showed a significant $\left({ }^{*} p<0.05\right)$ decrease in protein extracts from optic nerves $(\mathbf{a}, \mathbf{b})$ and retinas $(\mathbf{a}, \mathbf{d})$ of MHV-A59 infected mice 7 days post-inoculation, compared to control mice. MHV-A59 infected mice treated with SRTAW04 $\left(100 \mathrm{mg} / \mathrm{kg} /\right.$ day) showed a significant increase $\left({ }^{@} \mathrm{p}<0.05\right)$ of SDHb protein expression compared to untreated MHV-A59 infected mice. There is a significant decrease $\left({ }^{*} p<0.05\right)$ in expression of SOD2 $(n=4 /$ group) in optic nerves $(\mathbf{a}, \mathbf{c})$ and retinas $(\mathbf{a}, \mathbf{e})$ of MHV-A59 infected mice compared to control mice, and treatment with SRTAW04 significantly $\left({ }^{\circledR} p<0.05\right)$ attenuates that change. PGC1-a expression shows a significant $(* p<0.05)$ decrease in retinas $(\mathbf{a}, \mathbf{f})\left(\mathrm{n}=4\right.$ /group) during MHV-A59 infection and treatment with SRTAW04 for 7 days significantly $\left({ }^{\circledR} \mathrm{p}<0.05\right)$ increases the PGC1-a protein levels. 


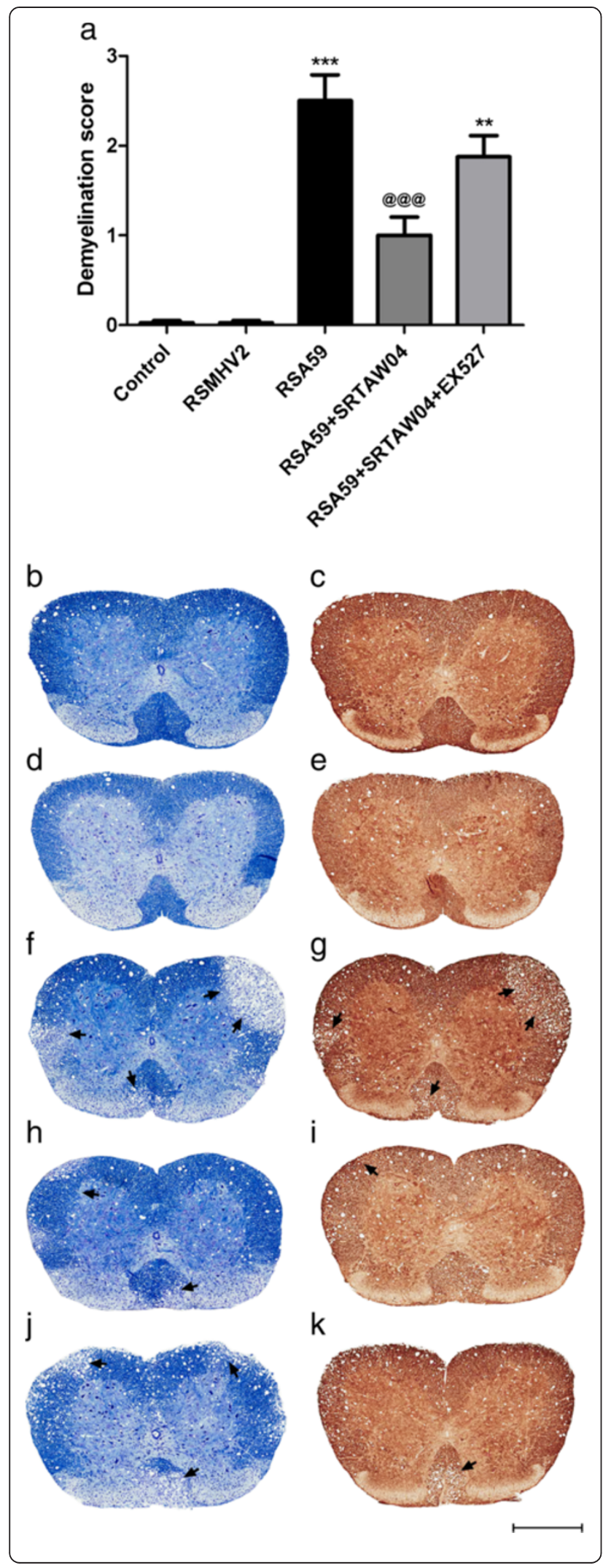

Figure 7 Effects of SRTAW04 on demyelination in the spinal cord. (a) Demyelination, scored on a relative scale by histologic evaluation of LFB stained spinal cords ( $n=4-5$ per group) taken 30 days after infection, shows a significant increase $\left({ }^{* *} p<0.001\right)$ in the RSA59 infected group compared to control and RSMHV2 infected mice. Treatment with SRTAW04 shows a significant reduction in the demyelinating score $(@ @ @<0.001)$. Treatment group that received SRTAW04 with EX527 showed a significant increase ( $\left.{ }^{@} \mathrm{p}<0.01\right)$ in demyelinating score compared to the group that received SRTAW04 alone, but no significant change compared to untreated RSA59 infected mice. LFB (left) and neurofilament (right) stained serial spinal cord sections from a representative $\mathbf{( b , c )}$ control, (d,e) RSMHV2 infected, $\mathbf{( f , g ) ~ R S A 5 9 ~ i n f e c t e d , ~ ( h , i ) ~ R S A 5 9 ~ i n f e c t e d , ~ w i t h ~ S R T A W 0 4 ~ t r e a t m e n t ~}$ and $\mathbf{( j , k ) ~ R S A 5 9 ~ i n f e c t e d , ~ w i t h ~ S R T A W 0 4 ~ + ~ E X 5 2 7 ~ t r e a t m e n t ~ m o u s e . ~}$ Neurofilament staining shows axonal loss limited to the areas of demyelination seen on LFB stained sections. Scale bars $500 \mu \mathrm{m}$ for $\mathbf{b}-\mathbf{k}$.

inhibitor EX527 did not show a significant reduction in demyelination (Figure $7 \mathrm{a}, \mathrm{f}-\mathrm{j}$ ). Serial sections were stained with antibodies for neurofilament and show focal axonal degeneration only in the areas of demyelination. (Figure 7c,e,g,i,k)

\section{Effects of SRTAW04 on inflammation in the spinal cord} To investigate whether SRTAW04 has an effect on inflammation, spinal cords from 7 day p.i. mice with MHV-A59 with or without treatment with $100 \mathrm{mg} / \mathrm{kg}$ SRTAW04 daily were cut into $5 \mu \mathrm{m}$ coronal sections and stained with H\&E and scored using a 3 point scale as described previously [21]. There was a significant increase in inflammation in MHV-A59 infected mice compared to controls (Figure 8a). Interestingly there was no significant difference observed between the inflammation score of the MHV-A59 infected group and the MHV-A59 infected mice treated with SRTAW04 (Figure 8a). No significant effect of SRTAW04 on inflammation was observed in H\&E stained sections of spinal cord from mice 30 days p.i. although inflammation levels are low (data not shown). To further investigate the effect of SRTAW04 on inflammation 30 days post infection, sections were stained with antiIba1 antibody, a macrophage/microglial marker. Results suggest there is difference in the area and number of microglia present, although all plaques contain Iba-1 stained cells regardless of SRTAW04 treatment (Figure 8b-f).

\section{Discussion}

Results confirm that infection with demylinating strains MHV-A59 and RSA59 induce optic neuritis in this model of MS, and for the first time demonstrate significant RGC loss occurs in this model as well. SIRT1 activating compound SRTAW04 significantly attenuates neuronal loss induced by MHV-A59 and RSA59 infection. Similar neuroprotective effects mediated by several SIRT1 activators were previously demonstrated in two different EAE models of MS, relapsing/remitting EAE in SJL/J mice $[23,24]$ and chronic EAE in C57BL/6 mice [22], but the 


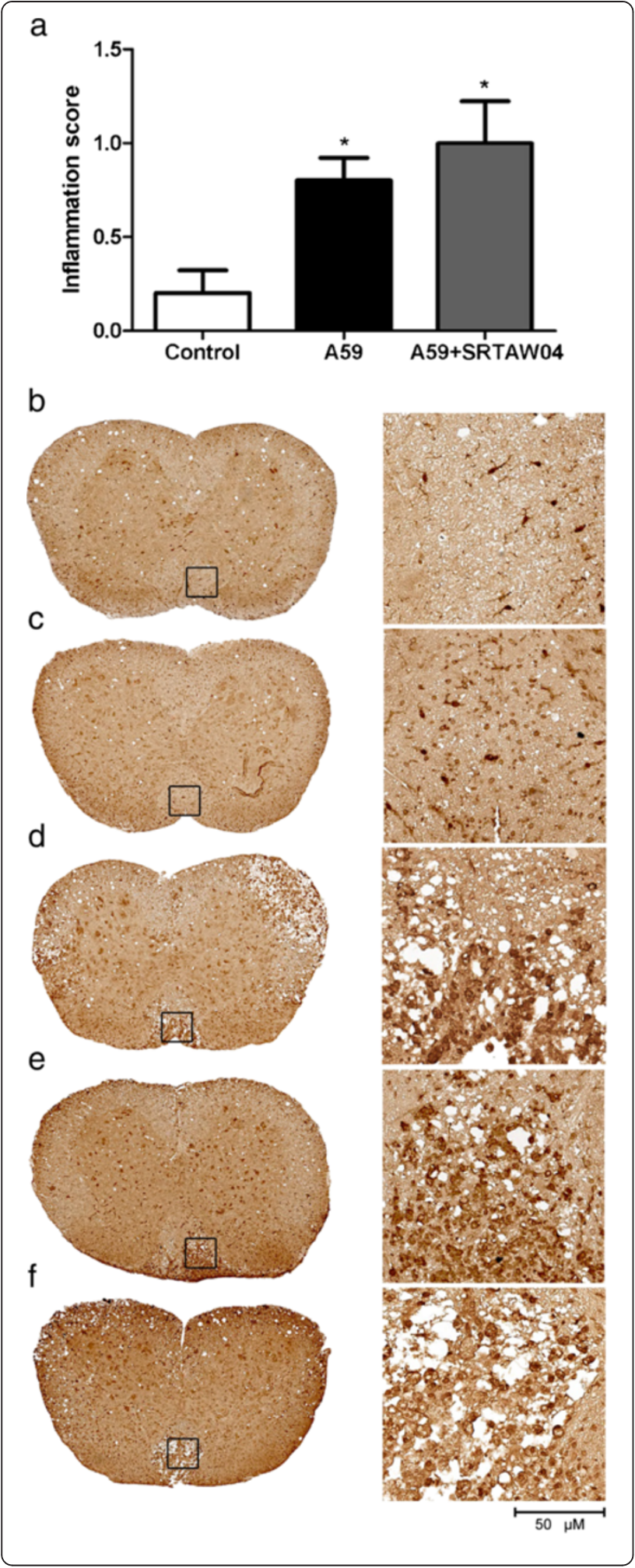

Figure 8 Effects of SRTAW04 on inflammation in the spinal cord. (a) Spinal cord sections ( $n=5$ per group) from 7 day post infected MHV-A59 and MHV-A59 infected group treated with $100 \mathrm{mg} / \mathrm{kg}$ SRTAW04 daily stained with H\&E were scored using a relative inflammation scale. There is a significant increase $\left({ }^{*} p<0.05\right)$ in the inflammation score in the MHV-A59 treated mice compared to controls. No significant difference in the inflammation score is observed between the MHV-A59 infected group and MHV-A59 infected mice treated with SRTAW04. By day 30 post-innoculation, limited inflammation is observed by H\&E staining in spinal cord, and inflammation that does occur consists almost exclusively of macrophages/microglia, thus sections ( $n=4-5$ per group) were immunostained for Iba1 to further assess relative levels of inflammation. A representative spinal cord section is shown from (b) control, (c) RSMHV2 infected, (d) RSA59 infected, (e) RSA59 infected + SRTAW04 treatment and (f) RSA59 infected + SRTAW04 + EX527 treatment mice. Boxes in low magnification sections (left column) indicate area shown at high magnification (right column). Increased foci of Iba1 positive cells are present in RSA59 infected mice with or without SRTAW04 treatment compared to control and RSMHV2 mice. Scale bars 50 um for $\mathbf{b}-\mathbf{f}$.

mechanism of these effects was not assessed beyond the role of activating SIRT1. The current results suggest SIRT1 activators can work by promoting mitochondrial function and reducing the accumulation of ROS. While such oxidative stress has been demonstrated previously in EAE $[28,30]$, it was not clear whether similar mechanisms would be found in the MHV induced demyelinating disease. While we found that SIRT1 activation is associated with reduced accumulation of ROS in optic nerves, one limitation of this study that will be addressed in future studies is that a causal relation of this effect has not been confirmed using ROS inhibitors as positive controls.

Interestingly, pathogenesis of neuronal injury begins with different triggers in EAE optic neuritis as compared to MHV optic neuritis, despite similar gross levels of inflammation. Axonal injury and loss of neurons in relapsing/ remitting EAE occurs secondary to inflammation [47,48], predominantly mediated by effector $\mathrm{T}$ cells, whereas neurotropic strains of MHV can directly infect neurons leading to direct injury, and leading to myelin stripping by activated microglia/macrophages [18]. MHV induced disease also occurs even in the absence of lymphocytes [49]. The ability of SIRT1 activators to prevent neuronal loss in both models therefore suggests they modulate a common mechanism of neurodegeneration downstream of the initial mechanisms of injury. SIRT1 activators appear to work by increasing expression of proteins involved in mitochondrial biogenesis and reduction of ROS, and indicate these are important targets for neuroprotective therapies. Consistent with this, SIRT1 activators were found to have similar neuroprotective effects in a model of traumatic optic nerve injury [38].

Resveratrol, a naturally-occurring polyphenolic compound, is the most studied SIRT1 activator [50]. A role for resveratrol and SIRT1 in neuroprotection has been 
suggested in other neurodegenerative processes besides demyelinating disease, including models of Alzheimer's disease [51,52], amyotrophic lateral sclerosis [52], and axotomized dorsal root ganglion cells [50]. However, resveratrol also modulates a variety of cellular signaling pathways independent of its ability to activate SIRT1, exerting a number of potentially beneficial effects including anti-carcinogenic properties, anti-inflammatory effects by inhibiting pro-inflammatory mediators and/or activated immune cells, and inhibition of inducible nitric oxide synthase and cycooxygenase-2 [53,54]. For the current studies, we used the SIRT1 activator SRTAW04 to avoid activating other pathways affected by resveratrol. In addition, compounds like SRTAW04 that activate SIRT1 by distinct mechanisms from resveratrol exert similar SIRT1 activation levels at concentrations an order of magnitude lower than resveratrol [33], and have shown good safety profiles in early phase clinical trials. In addition, we have shown previously that SRTAW04 itself prevents oxidative stress-induced loss of neurons in vitro [27].

Specific targets of the SIRT1 deacetylase that mediate observed changes in expression of mitochondrial enzymes require further study. SIRT1 was originally identified as a histone deacetylase $[55,56]$, leading to large changes in overall gene expression, but SIRT1 also has been found to deacetylate a number of other protein targets $[57,58]$, including transcription factors that may directly affect expression of specific genes. In addition, post-translational modifications of mitochondrial enzymes may further promote mitochondrial biogenesis, as SIRT1-mediated deacetylation of PGC1- $\alpha$ has been shown to do in muscle cells [26]. Results here show that transient increases in SIRT1 activity following administration of SRTAW04 were capable of providing long-term neuroprotective effects in MHV-A59 infected mice, suggesting that deacetylation of SIRT1 substrates may persist beyond the timing of acute SIRT1 activation.

The current studies show SRTAW04 exerts neuroprotective effects without suppressing gross levels of inflammation assessed by $H \& E$ staining, and confirmed by staining with macrophage/microglial markers. Unlike EAE models of MS mediated by T cells, in this virus induced model of MS inflammation consists almost exclusively of macrophages, as demonstrated in prior studies $[18,21,42]$. It is interesting that SIRT1 activation fails to block the migration of macrophages into the CNS, as prior studies have shown that SIRT1 activation can block the accumulation of macrophages in peripheral tissues [59], although even outside the CNS this effect appears to be tissue specific.

Evidence suggests neurologic dysfunction in MS occurs as a result of axonal degeneration [60,61], which may be dependent on or occur independently of chronic demyelination [62]. Our results show that SIRT1 activation can preserve RGCs and reduce axonal loss following infection with MHV. SRTAW04 treated mice that also received the SIRT1 inhibitor EX527 did not show a significant reduction in axonal loss or preserve RGCs, suggesting that the neuroprotective effect of SRTAW04 is mediated by SIRT1 activation. Furthermore, SIRT1 activation with SRTAW04 prevented myelin loss following MHV infection. These findings are consistent with a recent study [63] showing that mice overexpressing SIRT1 in neurons have reduced axonal loss and demyelination in the EAE model of MS. Together, results suggest SIRT1 promotes neuronal survival and prevents demyelination in CNS demyelinating diseases.

\section{Conclusions}

SIRT1 activating compounds represent potential new neuroprotective agents for demyelinating diseases. Results suggest SIRT1 activators can modulate oxidative stress, a common mechanism of neuronal injury, and begin to identify mechanisms that can be targeted for development of more specific neuroprotective therapies.

\section{Competing interests}

SRTAW04 was provided at no cost by Sirtris, a GSK Company, to KSS for these studies. No funding was provided by Sirtris for the studies, and KSS has no financial interests or relationships with Sirtris or related to its SRTAW04 compound. The authors have no other competing interests to declare.

\section{Authors' contributions}

RSK helped design these studies, performed all experiments, analyzed the data, and prepared the manuscript. KD assisted with induction of MHV disease, prepared tissue sections, and performed histological studies. JDS helped with experimental design, data analysis and preparation of the manuscript. KSS oversaw all aspects of these studies and was involved in experimental design, data analysis and manuscript preparation. All authors read and approved the final manuscript.

\section{Acknowledgements}

This work was supported by NIH grant EY015014, Research to Prevent Blindness, and the F. M. Kirby Foundation to KSS, and Research Grant BT/ PR14260/MED/30/437/2010 from Dept. of Biotechnology (DBT), India, IISER-K start up Fund and Research Grant RG3774A2/1 from the National Multiple Sclerosis Society, to JDS. We thank Sirtris, a GSK company, for kindly providing the SRTAW04 compound. The authors declare no competing financial interests.

Received: 29 November 2013 Accepted: 21 December 2013

Published: 2 January 2014

\section{References}

1. Noseworthy JH, Lucchinetti C, Rodriguez M, Weinshenker BG: Multiple sclerosis. N Engl J Med 2000, 343:938-952

2. Davie CA, Barker GJ, Webb S, Tofts PS, Thompson AJ, Harding AE, McDonald WI, Miller DH: Persistent functional deficit in multiple sclerosis and autosomal dominant cerebellar ataxia is associated with axon loss. Brain 1995, 118:1583-1592.

3. Losseff NA, Webb SL, O'Riordan Jl, Page R, Wang L, Barker GJ, Tofts PS, McDonald WI, Miller DH, Thompson AJ: Spinal cord atrophy and disability in multiple sclerosis. A new reproducible and sensitive MRI method with potential to monitor disease progression. Brain 1996, 119:701-708.

4. Losseff NA, Wang L, Lai HM, Yoo DS, Gawne-Cain ML, McDonald WI, Miller DH, Thompson AJ: Progressive cerebral atrophy in multiple sclerosis. A serial MRI study. Brain 1996, 119:2009-2019. 
5. Trip SA, Schlottmann PG, Jones SJ, Altmann DR, Garway-Heath DF, Thompson AJ, Plant GT, Miller DH: Retinal nerve fiber layer axonal loss and visual dysfunction in optic neuritis. Ann Neurol 2005, 58:383-391.

6. Fisher JB, Jacobs DA, Markowitz CE, Galetta SL, Volpe NJ, Nano-Schiavi ML, Baier ML, Frohman EM, Winslow H, Frohman TC, Calabresi PA, Maguire MG, Cutter GR, Balcer $L$ : Relation of visual function to retinal nerve fiber layer thickness in multiple sclerosis. Ophthalmology 2006, 113:324-332.

7. Johnson KP, Brooks BR, Cohen JA, Ford CC, Goldstein J, Lisak RP, Myers LW Panitch HS, Rose JW, Schiffer RB, Vollmer T, Weiner LP, Wolinsky JS: Copolymer 1 reduces relapse rate and improves disability in relapsing-remitting multiple sclerosis: results of a phase III multicenter, double-blind, placebo-controlled trial. Neurology 2001, 57:S16-S24.

8. Jacobs LD, Cookfair DL, Rudick RA, Herndon RM, Richert JR, Salazar AM, Fischer JS, Goodkin DE, Granger CV, Simon JH, Alam JJ, Bartoszak DM, Bourdette DN, Braiman J, Brownscheidle CM, Coats ME, Cohan SL, Dougherty DS, Kinkel RP, Mass MK, et al: Intramuscular interferon beta-1a for disease progression in relapsing multiple sclerosis. Ann Neurol 1996, 39:285-294.

9. Parry A, Corkill R, Blamire AM, Palace J, Narayanan S, Arnold D, Styles P, Matthews PM: Beta-Interferon treatment does not always slow the progression of axonal injury in multiple sclerosis. J Neurol 2003, 250:171-178.

10. Hickman SJ, Kapoor R, Jones SJ, Altmann DR, Plant GT, Miller DH: Corticosteroids do not prevent optic nerve atrophy following optic neuritis. J Neurol Neurosurg Psychiatry 2003, 74:1139-1141.

11. Gilden DH: Infectious causes of multiple sclerosis. Lancet Neurol 2005, 4:195-202.

12. Constantinescu CS, Hilliard B, Fujioka T, Bhopale MK, Calida D, Rostami AM: Pathogenesis of neuroimmunologic diseases, Experimental models. Immunol Res 1998, 17:217-227.

13. Kornek B, Storch MK, Weissert R, Wallstroem E, Stefferl A, Olsson T, Linington C, Schmidbauer M, Lassmann H: Multiple sclerosis and chronic autoimmune encephalomyelitis: a comparative quantitative study of axonal injury in active, inactive, and remyelinated lesions. Am J Pathol 2000, 157:267-276.

14. Meyer R, Weissert R, Diem R, Storch MK, de Graaf KL, Kramer B, Bahr M: Acute neuronal apoptosis in a rat model of multiple sclerosis. $J$ Neurosci 2001, 21:6214-6220.

15. Wujek JR, Bjartmar C, Richer E, Ransohoff RM, Yu M, Tuohy VK, Trapp BD: Axon loss in the spinal cord determines permanent neurological disability in an animal model of multiple sclerosis. J Neuropathol Exp Neurol 2002, 61:23-32.

16. Lavi E, Gilden DH, Wroblewska Z, Rorke LB, Weiss SR: Experimental demyelination produced by the A59 strain of mouse hepatitis virus. Neurology 1984, 34:597-603.

17. Lavi E, Gilden DH, Highkin MK, Weiss SR: MHV-A59 pathogenesis in mice. Adv Exp Med Biol 1984, 173:237-245.

18. Das Sarma J, Kenyon LC, Hingley ST, Shindler KS: Mechanisms of primary axonal damage in a viral model of multiple sclerosis. J Neurosci 2009, 29:10272-10280.

19. Arnold AC: Evolving management of optic neuritis and multiple sclerosis. Am J Ophthalmol 2005, 139:1101-1108.

20. Shindler KS, Guan Y, Ventura E, Bennett J, Rostami A: Retinal ganglion cell loss induced by acute optic neuritis in a relapsing model of multiple sclerosis. Mult Scler 2006, 12:526-532.

21. Shindler KS, Kenyon LC, Dutt M, Hingley ST, Das Sarma J: Experimental optic neuritis induced by a demyelinating strain of mouse hepatitis virus. J Virol 2008, 82:8882-8886.

22. Quinn TA, Dutt M, Shindler KS: Optic neuritis and retinal ganglion cell loss in a chronic murine model of multiple sclerosis. Front Neurol 2011, 2:50.

23. Shindler KS, Ventura E, Rex TS, Elliott P, Rostami A: SIRT1 Activation Confers Neuroprotection in Experimental Optic Neuritis. Invest Ophthalmol Vis Sci 2007, 48:3602-3609.

24. Shindler KS, Ventura E, Dutt M, Elliott P, Fitzgerald DC, Rostami A: Oral resveratrol reduces neuronal damage in a model of multiple sclerosis. J Neuroophthalmol 2010, 30:328-339.

25. Fonseca-Kelly Z, Nassrallah M, Uribe J, Khan RS, Dine K, Dutt M, Shindler KS: Resveratrol neuroprotection in a chronic mouse model of multiple sclerosis. Front Neurol 2012, 3:84

26. Lagouge M, Argmann C, Gerhart-Hines Z, Meziane H, Lerin C, Daussin F, Messadeq N, Milne J, Lambert P, Elliott P, Geny B, Laakso M, Puigserver P, Auwerx J: Resveratrol improves mitochondrial function and protects against metabolic disease by activating SIRT1 and PGC-1alpha. Cell 2006, 127:1109-1122.
27. Khan RS, Fonseca-Kelly Z, Callinan C, Zuo L, Sachdeva MM, Shindler KS: SIRT1 activating compounds reduce oxidative stress and prevent cell death in neuronal cells. Front Cell Neurosci 2012, 6:1-13.

28. Guy J, Ellis EA, Mames R, Rao NA: Role of hydrogen peroxide in experimental optic neuritis. A serial quantitative ultrastructural study. Ophthalmic Res 1993, 25:253-264

29. Dutta R, McDonough J, Yin X, Peterson J, Chang A, Torres T, Gudz T, Macklin WB, Lewis DA, Fox RJ, Rudick R, Mirnics K, Trapp BD: Mitochondrial dysfunction as a cause of axonal degeneration in multiple sclerosis patients. Ann Neurol 2006, 59:478-489.

30. Qi X, Lewin AS, Sun L, Hauswirth WW, Guy J: Suppression of mitochondrial oxidative stress provides long-term neuroprotection in experimental optic neuritis. Invest Ophthalmol Vis Sci 2007, 48:681-691.

31. Das Sarma J, Fu L, Weiss SR, Lavi E: Demyelination determinants in the $\mathrm{S}$ gene of MHV. Adv Exp Med Biol 2001, 494:133-137.

32. Das Sarma J, lacono K, Gard L, Marek R, Kenyon LC, Koval M, Weiss SR: Demyelinating and nondemyelinating strains of mouse hepatitis virus differ in their neural cell tropism. J Virol 2008, 82:5519-5526.

33. Milne JC, Lambert PD, Schenk S, Carney DP, Smith JJ, Gagne DJ, Jin L, Boss O, Perni RB, Vu CB, Bemis JE, Xie R, Disch JS, Ng PY, Nunes JJ, Lynch AV, Yang H, Galonek H, Israelian K, Choy W, et al: Small molecule activators of SIRT1 as therapeutics for the treatment of type 2 diabetes. Nature 2007, 450:712-716.

34. Cohen-Kfir E, Artsi H, Bajayo A, Gabet Y, Gurt I, Kalish N, Shahar R, Dresner-Pollak R: The Sirtuin 1 Activator SRTAW04 restores Bone Mass and Structure in Ovariectomized Mice A Potential Novel Therapy for Osteoporosis. Endocr Rev 2013, 34:OR24-26.

35. Dietrich MO, Antunes C, Geliang G, Liu ZW, Borok E, Nie Y, Xu AW, Souza DO, Gao Q, Diano S, Gao XB, Horvath TL: Agrp neurons mediate Sirt1's action on the melanocortin system and energy balance: roles for Sirt1 in neuronal firing and synaptic plasticity. J Neurosci 2010, 30:11815-11825.

36. Peck B, Chen CY, Ho KK, Di Fruscia P, Myatt SS, Coombes RC, Fuchter MJ, Hsiao CD, Lam EW: SIRT inhibitors induce cell death and p53 acetylation through targeting both SIRT1 and SIRT2. Mol Cancer Ther 2010, 4:844-855.

37. Yamaguchi $\mathrm{H}$, Woods NT, Piluso LG, Lee HH, Chen J, Bhalla KN, Monteiro A, Liu X, Hung MC, Wang HG: p53 acetylation is crucial for its transcriptionindependent proapoptotic functions. J Biol Chem 2009, 284:11171-83.

38. Zuo L, Khan RS, Lee V, Dine K, Wu W, Shindler KS: SIRT1 Promotes RGC Survival and Delays Loss of Function Following Optic Nerve Crush. Invest Ophthalmol Vis Sci 2013, 54:5097-5102.

39. Salinas-Navarro M, Mayor-Torroglosa S, Jimenez-Lopez M, Aviles-Trigueros M, Holmes TM, Lund RD, Villegas-Perez MP, Vidal-Sanz M: A computerized analysis of the entire retinal ganglion cell population and its spatial distribution in adult rats. Vision Res 2009, 49:115-126.

40. Forte M, Gold BG, Marracci G, Chaudhary P, Basso E, Johnsen D, Yu X, Fowlkes J, Rahder M, Stem K, Bernardi P, Bourdette D: Cyclophilin D inactivation protects axons in experimental autoimmune encephalomyelitis an animal model of multiple sclerosis. Proc Natl Acad Sci 2007, 18:7558-7563.

41. Das Sarma J, Scheen E, Seo SH, Koval M, Weiss SR: Enhanced green fluorescent protein expression may be used to monitor murine coronavirus spread in vitro and in the mouse central nervous system. J Neurovirol 2002, 8:381-391.

42. Shindler KS, Chatterjee D, Biswas K, Goyal A, Dutt D, Nassrallah M, Khan RS, Das Sarma J: Macrophage-mediated optic neuritis induced by retrograde axonal transport of spike gene recombinant mouse hepatitis virus. J Neuropathol Exp Neurol 2011, 70:470-480.

43. Ackrell BA, Maguire JJ, Dallman PR, Kearney EB: Effect of iron deficiency on succinate- and NADH-ubiquinone oxidoreductases in skeletal muscle mitochondria. J Biol Chem 1984, 259:10053-10059.

44. Baysal BE: A phenotypic perspective on Mammalian oxygen sensor candidates. Ann N Y Acad Sci 2006, 1073:221-233.

45. Suski JM, Lebiedzinska M, Bonora M, Pinton P, Duszynski J, Wieckowski MR: Relation between mitochondrial membrane potential and ROS formation. Methods Mol Biol 2012, 810:183-205.

46. Russell LK, Mansfield CM, Lehman JJ, Kovacs A, Courtois M, Saffitz JE: Cardiac-specific induction of the transcriptional coactivator peroxisome proliferator-activated receptor gamma coactivator-1alpha promotes mitochondrial biogenesis and reversible cardiomyopathy in a developmental stage-dependent manner. Circ Res 2004, 94:525-533.

47. Shindler KS, Ventura E, Dutt M, Rostami AM: Inflammatory demyelination induces axonal injury and retinal ganglion cell apoptosis in experimental optic neuritis. Exp Eye Res 2008, 87:208-213. 
48. Dutt M, Tabuena P, Ventura E, Rostami AM, Shindler KS: Timing of corticosteroid therapy is critical to prevent retinal ganglion cell loss in experimental optic neuritis. Invest Ophthalmol Vis Sci 2010, 51:1439-1445.

49. Matthews AE, Lavi E, Weiss SR: Neither B cells nor T cells are required for CNS demyelination in mice persistently infected with MHV-A59. J Neurovirol 2002, 8:257-264.

50. de la Lastra CA, Villegas I: Resveratrol as an anti-inflammatory and anti-aging agent: mechanisms and clinical implications. Mol Nutr Food Res 2005, 49:405-430.

51. Parker JA, Arango M, Abderrahmane S, Lambert E, Tourette C, Catoire $\mathrm{H}$, Néri C: Resveratrol rescues mutant polyglutamine cytotoxicity in nematode and mammalian neurons. Nat Genet 2005, 37:349-350.

52. Kim D, Nguyen MD, Dobbin MM, Fischer A, Sananbenesi F, Rodgers JT, Delalle I, Baur JA, Sui G, Armour SM, Puigserver P, Sinclair DA, Tsai LH: SIRT1 deacetylase protects against neurodegeneration in models for Alzheimer's disease and amyotrophic lateral sclerosis. EMBO J 2007, 26:3169-3179

53. Araki T, Sasaki Y, Mill brandt J: Increased nuclear NAD biosynthesis and SIRT1 activation prevent axonal degeneration. Science 2004, 305:1010-1013.

54. Jang M, Cai L, Udeani GO, Slowing KV, Thomas CF, Beecher CW, Fong HH, Farnsworth NR, Kinghorn AD, Mehta RG, Moon RC, Pezzuto JM: Cancer chemopreventive activity of resveratrol, a natural product derived from grapes. Science 1997, 275:218-220.

55. Imai S, Armstrong CM, Kaeberlein M, Guarente L: Transcriptional silencing and longevity protein Sir2 is an NAD-dependent histone deacetylase. Nature 2000, 403:795-800.

56. Landry J, Sutton A, Tafrov ST, Heller RC, Stebbins J, Pillus L, Sternglanz R: The silencing protein SIR2 and its homologs are NAD-dependent protein deacetylases. Proc Natl Acad Sci U S A 2000, 97:5807-5811.

57. Blander G, Guarente L: The Sir2 family of protein deacetylases. Annu Rev Biochem 2004, 73:417-435.

58. Porcu M, Chiarugi A: The emerging therapeutic potential of sirtuin-interacting drugs: from cell death to lifespan extension. Trends Pharmacol Sci 2005, 26:94-103.

59. Lee SM, Yang H, Tartar DM, Gao B, Luo X, Ye SQ, Zaghouani H, Fang D: Prevention and treatment of diabetes with resveratrol in a non obese mouse model of type 1 diabetes. Diabetologia 2011, 54:1136-1146.

60. Budde MD, Kim JH, Liang HF, Russell JH, Cross AH, Song SK: Axonal injury detected by in vivo diffusion tensor imaging correlates with neurological disability in a mouse model of multiple sclerosis. NMR Biomed 2008, 21:589-597.

61. Budde MD, Xie M, Cross AH, Song SK: Axial diffusivity is the primary correlate of axonal injury in the experimental autoimmune encephalomyelitis spinal cord: a quantitative pixelwise analysis. J Neurosci 2009, 29:2805-2813.

62. Dandekar AA, Wu GF, Pewe L, Perlman S: Axonal damage is T cell mediated and occurs concomitantly with demyelination in mice infected with a neurotropic coronavirus. J Virol 2001, 75:6115-6120.

63. Nimmagadda VK, Bever $C T$, Vattikunta NR, Talat $S$, Ahmad V, Nagalla NK, Trisler D, Judge SI, Royal W 3rd, Chandrasekaran K, Russell JW, Makar TK: Overexpression of SIRT1 protein in neurons protects against autoimmune encephalomyelitis through activation of multiple SIRT1 targets. J Immunol 2013, 190:4595-4607.

doi:10.1186/2051-5960-2-3

Cite this article as: Khan et al:: SIRT1 Activating compounds reduce oxidative stress mediated neuronal loss in viral induced CNS demyelinating disease. Acta Neuropathologica Communications 2014 2:3.

\section{Submit your next manuscript to BioMed Central and take full advantage of:}

- Convenient online submission

- Thorough peer review

- No space constraints or color figure charges

- Immediate publication on acceptance

- Inclusion in PubMed, CAS, Scopus and Google Scholar

- Research which is freely available for redistribution 